\title{
Investigating the Status of Health Promoting Behaviors and Its relation to Self-Efficacy and Social Support in Female Heads of Suburban Households of Urmia City
}

\author{
Fatemeh Mogadam Tabrizi, Naser Shaykhi, Soheila Najafi
}

1. $M S c$

\section{Article Info}

Received: 2018/10/14;

Accepted: 2018/12/25;

Published Online: 2019/08/28

10.30699/sjhnmf.27.6.394

Original Article

Use your device to scan and read the article online

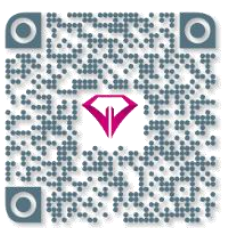

ABSTRACT

Introduction: Health promoting behaviors are one of the key determinants of health. One of the most important situations in which health promoting behaviors are of particular importance, is about female marginalized households. Therefore, this study was conducted to determine the mean scores of health promoting behaviors and its six dimensions, and also its relation to self-efficacy, social support and demographic factors in the women-headed families of Urmia suburb in 2017.

Methods: This was a descriptive-analytic study and its statistical population was all the female heads of the suburban families of Urmia of which 384 were selected. Data were collected through demographic questionnaires, perceived social support, general self-efficacy and Walker Health Promoting Behavior Inventory. Descriptive statistics including mean and standard deviation were used to describe descriptive characteristics and, Pearson and Kendall's correlation tests were used to describe analytical features.

Results: The mean of total health promoting behaviors was $111.62 \pm 20.45$. Selfefficacy, perceived social support and demographic characteristics of marriage and education had a significant positive correlation with health promoting behaviors $(P<0.001)$, but there was no significant positive correlation between occupation and age with health promoting behaviors.

Conclusion: According to the findings of this research, health authorities and health care providers can found self-efficacy increase for female heads of households by designing health promoting education programs. Also governmental organizations and families with supplying necessary emotional supports can provide an area of social support increase and consequently, a change in behavior, for suburbanized female heads of households.

Keywords: Health promoting behaviors, Female-headed households, Suburbanization, Selfefficacy, Social support

\section{Corresponding Information: \\ Soheila Najafi, . Email: soheilanajjafi@gmail.com}

Copyright $\odot 2020$, This is an original open-access article distributed under the terms of the Creative Commons Attribution-noncommercial 4.0 International License which permits copy and redistribution of the material just in noncommercial usages with proper citation.

\section{How to Cite This Article:}

Najafi S, Mogadam tabrizi F, Shaykhi N. Investigating the Status of Health Promoting Behaviors and Its relation to Self-Efficacy and Social Support in Female Heads of Suburban Households of Urmia City. Avicenna J Nurs Midwifery care. 2019; 27 (6) :394-404 


\title{
بررسى وضعيت رفتارهاى ارتقاء دهندهُ سلامتى و ارتباط آن با خودكار آمدى و حمايت اجتماعى در زنان سريرست خانوار حاشيه شهر اروميه
}

فاطمه مقدم تبريزى'، ناصر شيخى '، سهيلا نجفى ب*

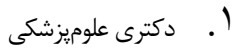

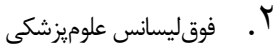

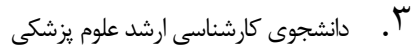

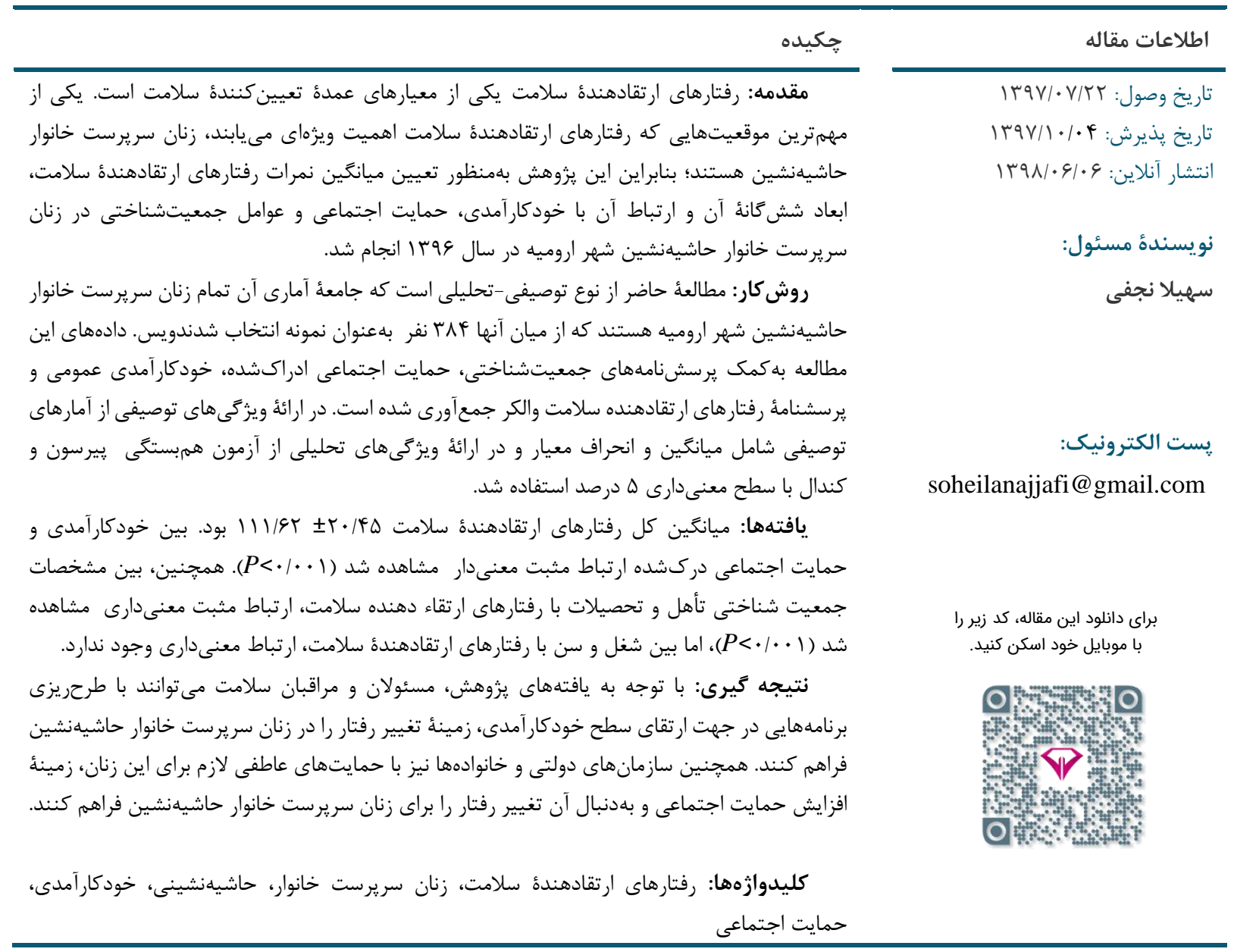

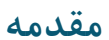

احسن انجام دهند، بايد سطح سلامت و رفاه خود را حفظ كنند

و ارتقا دهند [ب].

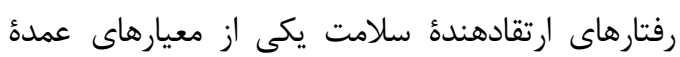

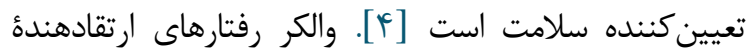
سلامت را جنين تعريف كرده است: الكَويى جندبعدى از ادراكات و اعمال آغازشده با انخَيزه خود شخص كه بهد به تداوم و تقويت
زنان زيربناى سلامت خانوادهها و جوامع هستند و اهميت

ويزهاى در تأمين و استمرار سلامت خانواده و جامعله دارند [ [1]. طبق بيانيئ سازمان بهداشت جهانى بهرهمندى ازئ بار بالاترين سطح

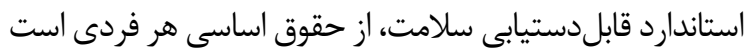

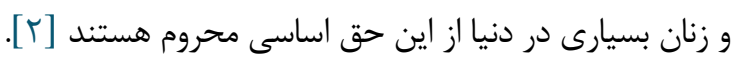

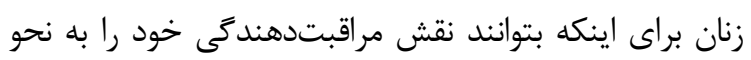


افراد جامعه است [ها، 1]]. با توجه به اينكه زنان سريرست

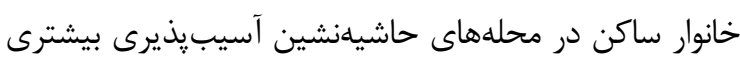

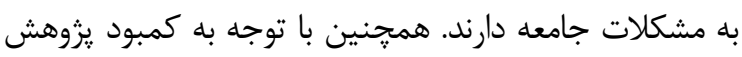
در زمينه رفتارهاى ارتقادهنده سلامت درمورد اين زنان، مطالعه

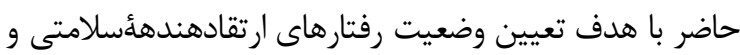

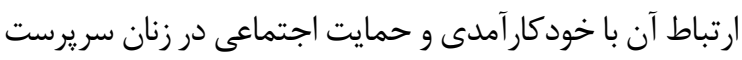
خانوار حاشيهنشين انجام شده است.

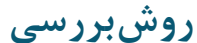

يزوهش حاضر توصيفى-تحليلى و مقطعى است كه در

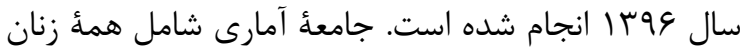
سريرست خانوار حاشيهنشين شهرستان اروميه بودند. حجم

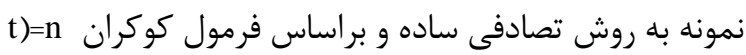
اين مطالعه، معيارهاى ورود به يزوهش شامل ساكن حاشيئ شهر اروميه، سريرست خانواربودن زن در زمان تكميل يرسشنامهاه، رضايتمندى براى شركت در مطالعه و نداشتن سابقؤ بسترى ندري در بخش روان بود. افرادى كه تمايلى به شركت در مطالعه

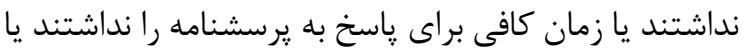

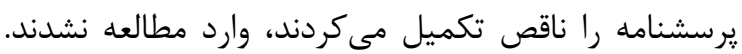
بخش اول يرسشنامه شامل flf إرسش درباره مشخصات جمعيت شناختى زنان سريرست خانوار حاشيهنشين بود.

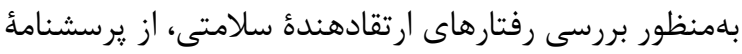

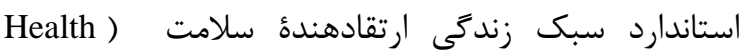
Promotion Lifestyle Profile II = HPLP-II اين برسشنامه راوالكر و همكاران (9MV (1) طراحى كردهاند. در يزوهش ما از نسخة ايرانى Mohhamadi و همكاران

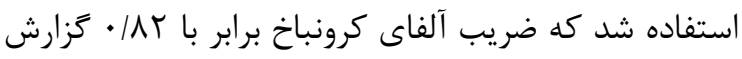
شده است [19]. يرسشنامة سبك زندگى ارتقادهنده سلامت

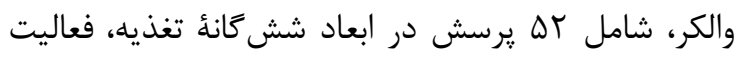
جسمى، مديريت استرس، رشد روحى، مسئوليتيذيرى إنى

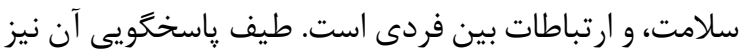

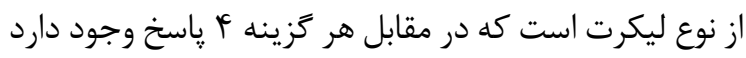

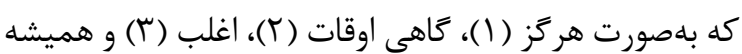

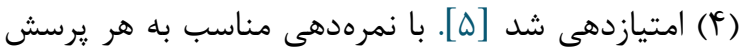

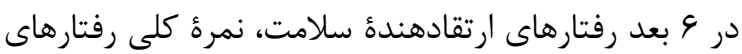

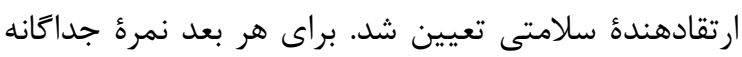

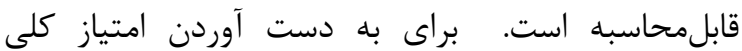

سطح سلامت و خودشكوفايى شخص كمك مى كند و داراى شش بعد تغذيه، فعاليت فيزيكى، مديريت استرس، روابط بين

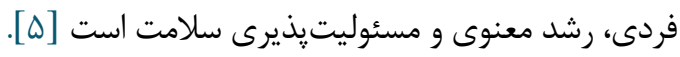
امروزه نقش عوامل فردى، رفتارى و اجتماعى در ايجاد رفتارهاى سالم مطالعه شده است. يكى از فاكتورهاى فردى و

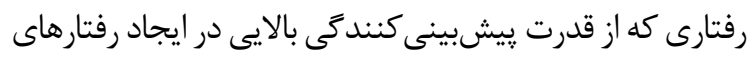

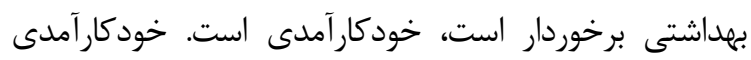
اطمينانخاطرى است كه شخص دربارهؤ فعاليت خاصى برى احساس مى كند [9]. افرادى كه خودكارآمدى زيادى دارئ دارند،

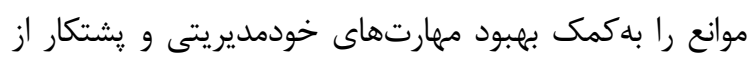
بين مىبرند، در برابر مشكلات ايستادكى مى كنند و بر امور

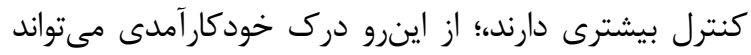

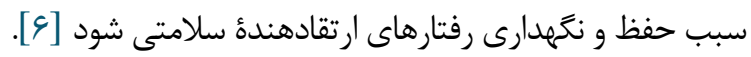

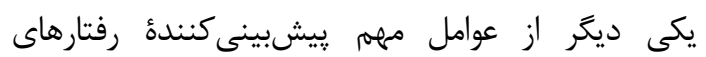

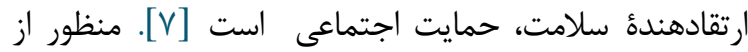

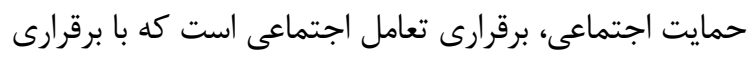

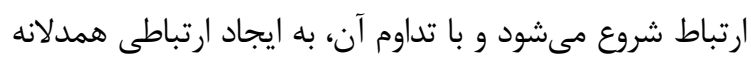

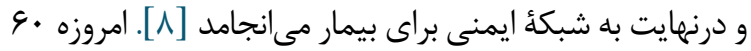

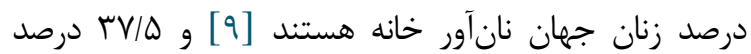

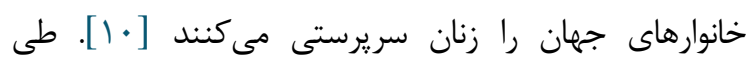
سال هاى اخير، تعداد زنان سريرست خانوار در كشورمان به على متعددى مانند افزايش طلاق، كاهش ميزان ازدواج، مر كرومير و

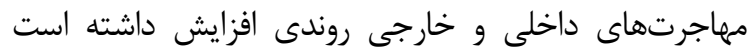

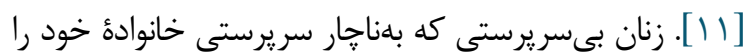
بر عهده دارند، جزء اقشار آسيبذيذير جامعه هستند؛ زيرا با باريا

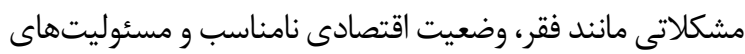

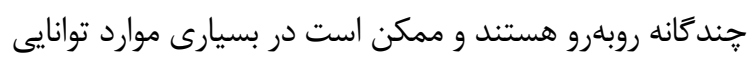
حفظ و ارتقاى سلامت خود را نداشته باشند [1 I I].

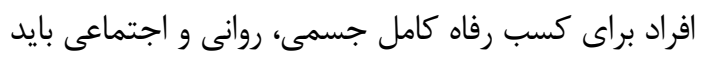

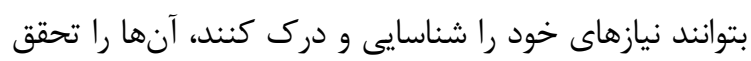
ببخشند و محيط خود را تغيير دهند يا با آن سازكار شوند. تأكيد اين تعريف بر ارتقاى سلامت فرايندى است كهيط كه افراد

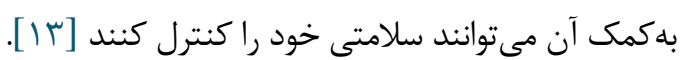

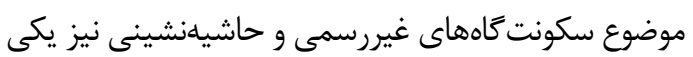
از معضلات شهرهاى بزرى است كه از طريق ايجاد يك محيط

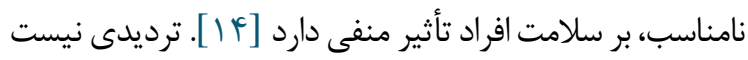
كه يكى از راهكارهاى مطلوب براى بهبود و ارتقاى كيفيت

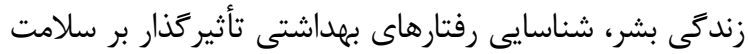


شد. روش گردآورى دادهها براساس مصاحبة حضورى و

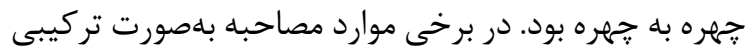

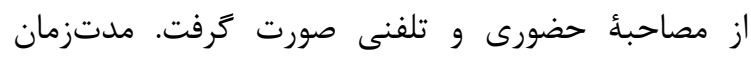

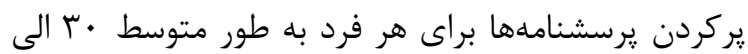

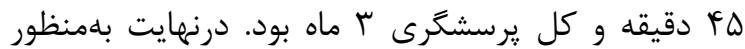

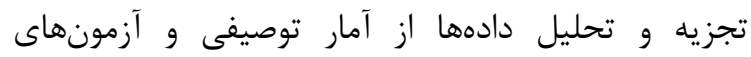
همبستخى ييرسون و كندال و رگرسيون خطى، با سطح معنى دارى ه درصد، با بهرهگيرى از نرمافزار SPSS نسخئ ها (SPSS Inc., Chicago, Illinois, USA) استفاده شد.

بافته ها

بيشتر زنان سريرست خانوار حاشئُ شهر كه در اين يزوهش

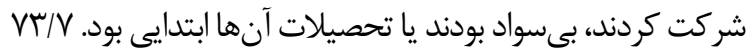

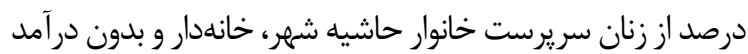

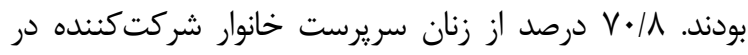
يزوهش، وضعيت اقتصادى خود را در حد دخل كمتر از خرج

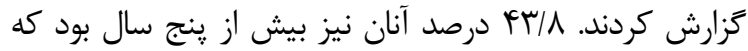

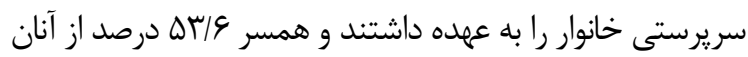

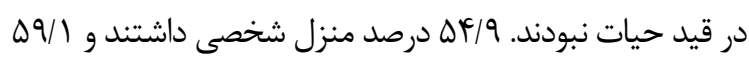
درصد اوقات فراغت نداشتند. همجنين سF/DF درصد بيمارى مزمن داشتند كه از اين مقدار 1/N/ درصد به بيمارى فشارخون

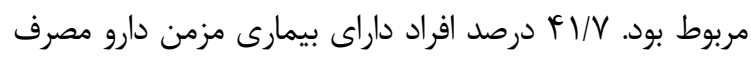
مى كردند. \&N/T درصد اعضاى تحت تكفل زنان سريرست خانوار سالم بودند و VV/I درصد بيمه نداشتند و / ه9/I درصد زنان

سريرست خانوار درآمد متغير داشتند. (جدول () ).
يرسشنامه، مجموع امتيازات همأ يرسشها با هم جمع شد. در هر بعد نمره بالاتر نشاندهنده وضعيت بهتر بود.

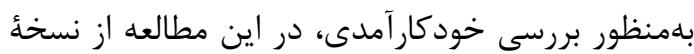

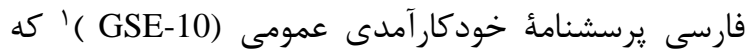
Rajabi

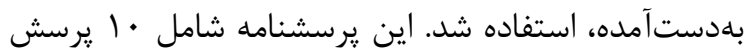
در مقياس درجهبندى ليكرت از لاصلاً صحيح نيست تا كاملاً صحيح است" و محدؤه نمره كل قابل كسب از اين مقياس

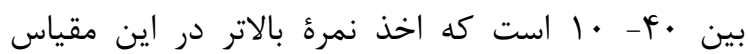
نشاندهنده خود كار آمدى عمومى بالاتر است.

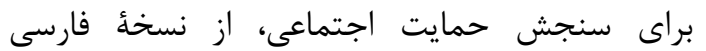

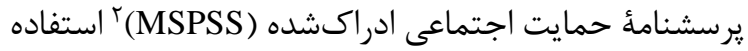

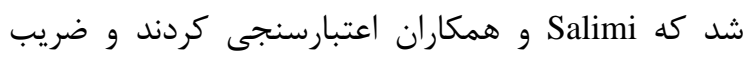
آلفاى كرونباخ سه بعد حمايت اجتماعى دريافتشده از سوى هدي

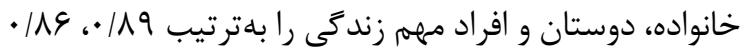

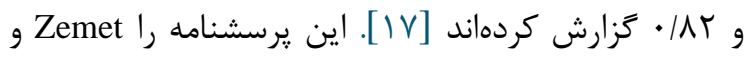
همكاران در سال 1911 بهمنظور سنجش حمايت اجتماعى ادراكشده از سوى خانواده، دوستان و افراد مهرم زندگى فرد تهيه كردهاند. اين مقياس זا گويه دارد و ياسخكَ نظر خود

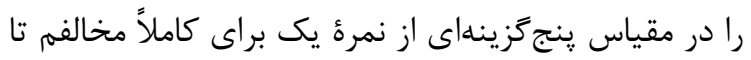

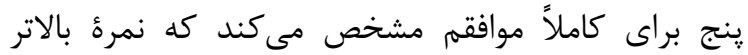
نشاندهنده وضعيت بهتر و نمره پايين نشاندهنده وضعيت مهري

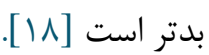
نمونهَيرى به روش نمونهَيرى جدول اسداد اعداد تصادفى و براساس معيارهاى ورود به مطالعه از زنان سريرست خانوار تحت يوشش مراكز خدمات جامع سلامت حاشيئ شهر انجام

جدول ا. توزيع فراوانى مشخصات جمعيتشناختى كيفى

\begin{tabular}{|c|c|c|}
\hline تعداد (درصد) & \multicolumn{2}{|c|}{ متغير } \\
\hline$\Lambda 1(Y M / I)$ & كمتر از هَّ سال & \multirow{4}{*}{ 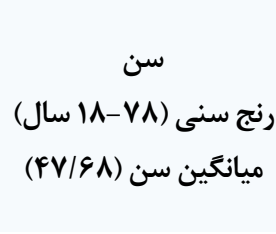 } \\
\hline$\Lambda T(Y \backslash / F)$ & هז تا هף سال & \\
\hline $11 \Delta(r 9 / 9)$ & هُ تا هـ سال & \\
\hline $1.9(T V / G)$ & بالاى هـ سال & \\
\hline $\mid \& V(F T / Q)$ & بىسواد & \\
\hline$|r|(r Y / Q)$ & ابتدايى & تحמטلע" \\
\hline$V r(19)$ & متوسطه & لحصيل \\
\hline$\|(r / \Psi)$ & تحصيلات دانشگاهى & \\
\hline
\end{tabular}

${ }^{2}$. the Multidimensional Scale of Perceived Social Support (MSPSS)
1. General Self-Efficacy Scale (10)

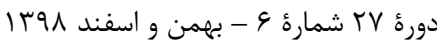
مجله مراقبت يرستارى و مامايى ابنسينا 


\begin{tabular}{|c|c|c|}
\hline تعداد (درصد) & متغير & \\
\hline $9(1 / 9)$ & مجرد & \multirow{4}{*}{ وضعيت تأهل } \\
\hline$\| 9(\Gamma \cdot / r)$ & متأهل (معلول، از كارافتاده، زندانى، معتاد، ترى كرده) & \\
\hline$r \cdot \varphi(\Delta r / \varphi)$ & فوت همسر & \\
\hline$\Delta S(\mid Y / Q)$ & مطلقه & \\
\hline $1 \cdot 1(\Gamma / T)$ & 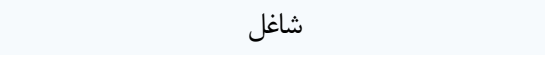 & \multirow{2}{*}{ وضعيت اشتغال } \\
\hline rAY $(V T / V)$ & 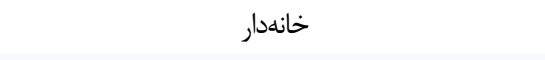 & \\
\hline $11(r / 9)$ & 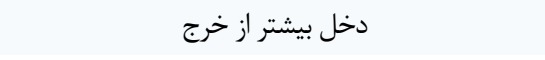 & \multirow{3}{*}{ وضعيت اقتصادى } \\
\hline $1 \cdot 1(T g / \Gamma)$ & 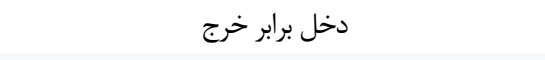 & \\
\hline $\operatorname{TVT}(V \cdot \mid \Lambda)$ & 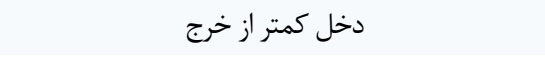 & \\
\hline$r \|(\Delta F / q)$ & 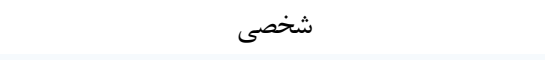 & \multirow{2}{*}{ وضعيت مسكن } \\
\hline $\mid V r(F \Delta / 1)$ & استيجارى & \\
\hline$V T(\mid N / \Lambda)$ & كمتر از يك سال & \multirow{3}{*}{ مدت سريرستى } \\
\hline $\mid F F(r V / D)$ & 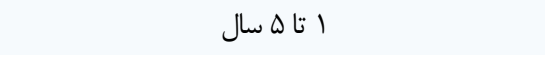 & \\
\hline $1 \varepsilon \wedge(F T / \Lambda)$ & بيشتر از ه سال & \\
\hline
\end{tabular}

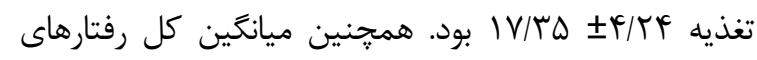

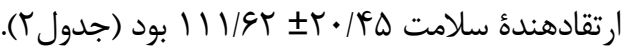
ميانگين نمره حمايت اجتماعى زنان سريرست خانوار

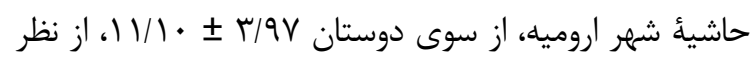

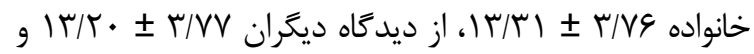
ميانگين نمرة حمايت اجتماعى كل و

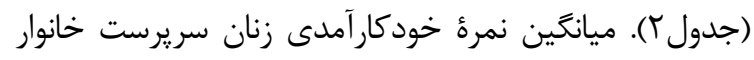

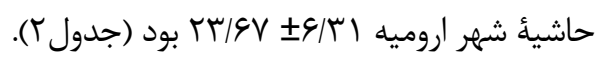

تغذيه، فعاليت جسمى، مديريت استرس، رشد روحى، مسئوليت يذيرى سلامتى و ارتباطات بينفردى در ارتباط با ابعاد

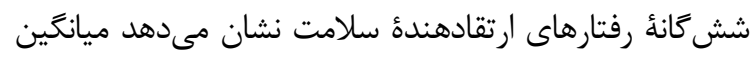

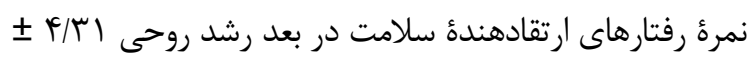

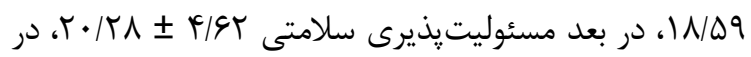
بعد ارتباط بينفردى

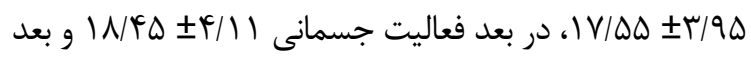
جدول r. ميانًَين نمرات رفتارهاى ارتقادهنده سلامت در ابعاد ششَانه آن و خودكار آمدى و حمايت اجتماعى در زنان سريرست خانوار حاشيهنشين شهر

\begin{tabular}{|c|c|c|c|c|}
\hline حداكثر نمره & حداقل نمره & انحراف معيار & 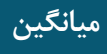 & 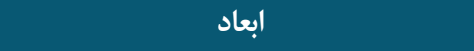 \\
\hline 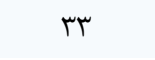 & $1 \cdot$ & e/r & $1 N / 09$ & 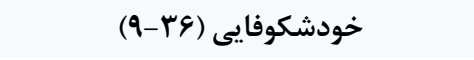 \\
\hline me & $1 \cdot$ & F/gT & $r \cdot / T \Lambda$ & مسئوليتيذيرى در مورد سلامت (\& (-9) \\
\hline mt & $1 \cdot$ & $f / \Delta 9$ & $r \cdot / / r$ & حمايت بين فردى (צ-r-9) \\
\hline r & 9 & $r / 9 \Delta$ & $I V / \Delta \Delta$ & مديريت استرس (Tr-M) \\
\hline rq & 9 & $4 / 11$ & IV/VT & ورزش (rr-1) \\
\hline r & 9 & F/TF & $I V / r \Delta$ & تغذيه (צ-19) \\
\hline $1 \wedge \Delta$ & st & $r \cdot / 4 \Delta$ & $111 / 94$ & رفتار هاى ارتقاء دهنده سلامت كل \\
\hline r. & 1 . & $91 \cdot r$ & rM/Q. & خودكار آمدى (•F-1) \\
\hline 4. & it & $9 / T^{F}$ & $r V|q|$ & حمايت اجتماعى (•४-Y|) \\
\hline$r \cdot$ & f & r/9V & $11 / 1$ & حمايت اجتماعى از سوى دوستان (•r-Y) \\
\hline$r \cdot$ & f & r/VG & $|r / \mu|$ & حمايت اجتماعى از سوى خانواده (•r-F) \\
\hline r. & r & $r / V V$ & $\mid r / T$. & حمايت اجتماعى از سوى ديغران (•F-Y) \\
\hline
\end{tabular}


براى بررسى ارتباط رفتارهاى ارتقادهنده سلامتى با عوامل

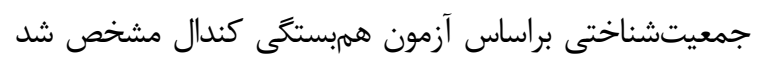

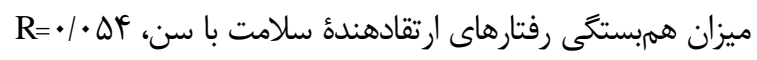

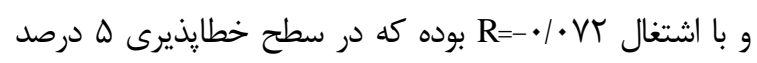

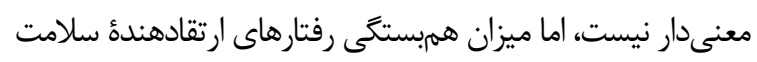

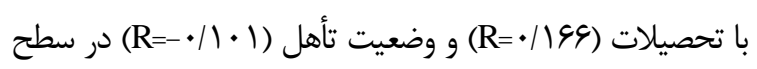

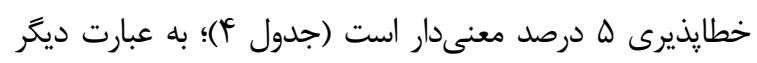

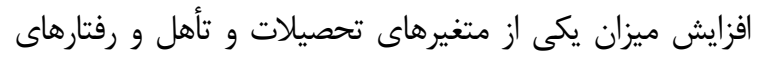
ارتقادهندة سلامتى رابطداى مستقيم با يكديكر دارند، اما با اشتغال و سن ارتباط مستقيمى ندارند.
براى بررسى ارتباط رفتارهاى ارتقادهندئ سلامتى با ميزان

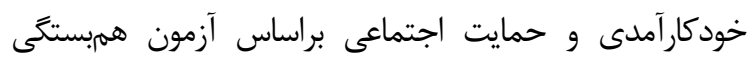

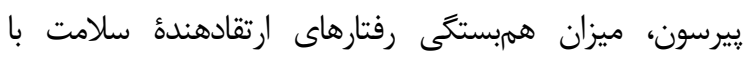

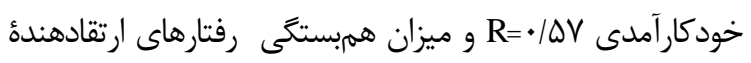

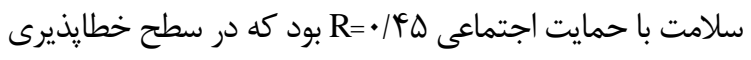

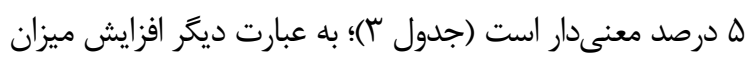

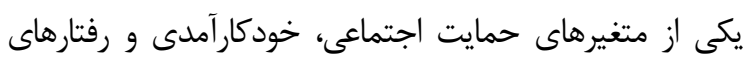

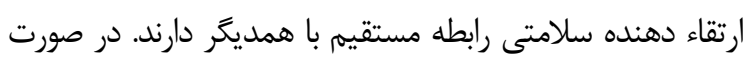

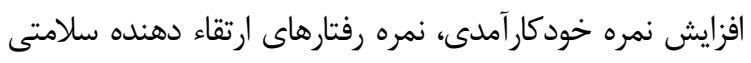

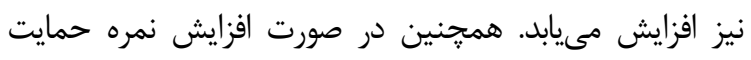
اجتماعى، نمره رفتارهاى ارتقاء دهنده سلامتى نيز افزايش مىيابد.

جدول س. بررسى ميزان همبستخى رفتارهاى ارتقادهندهُ سلامتى با خودكار آمدى و حمايت اجتماعى

\begin{tabular}{|c|c|c|c|}
\hline خود كار آمدى & حمايت اجتماعى & نتايج آزمون بيرسون & \\
\hline$\cdot / \Delta V$ & $\cdot / 4 a$ & ضريب همبستكى (r) & \multirow{2}{*}{ رفتارهاى ار تقادهنده سلامت } \\
\hline$\cdot 1 \cdot \cdot 1$ & $\cdot 1 \cdot \cdot 1$ & احتمال معنى دارى & \\
\hline
\end{tabular}

جدول شماره F. بررسى ارتباط رفتارهاى ار تقاء دهنده سلامت با مشخصات جمعيت شناختى

\begin{tabular}{|c|c|c|}
\hline \multicolumn{3}{|c|}{ رفتارهاى ار تقاء دهنده سلامت } \\
\hline احتمال معنى دارى & ضريب همبستخى * & متغيرها \\
\hline . llaf & $\cdot \mid \cdot \Delta F$ & سن \\
\hline$\cdot 1 \cdot \cdots$ & .1199 & تحصيلات \\
\hline$\cdot 1 \cdot \cdot 9$ & $-\cdot 11 \cdot 1$ & تأهل \\
\hline$\cdot 1 \cdot \wedge \mathrm{V}$ & $-\cdot 1 \cdot V T$ & اشتغال \\
\hline
\end{tabular}

* آزمون همبستخى كندال

وجود مراكز خدمات جامع سلامت در حاشيئ شهر، بيگيرى

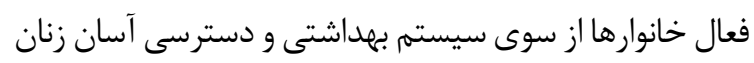

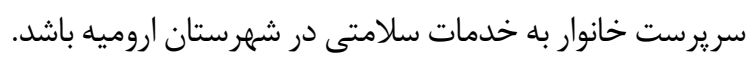

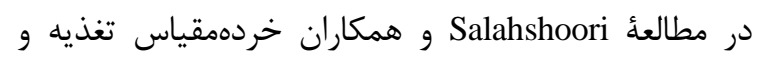

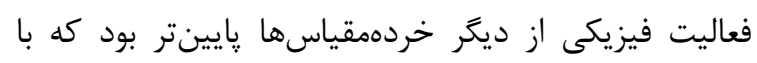

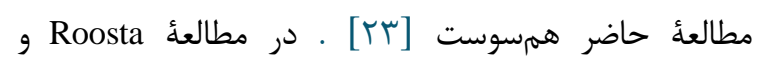
همكاران، بعد تغذيه بالاترين نمره را داشت كه با مطالعئ حاضر

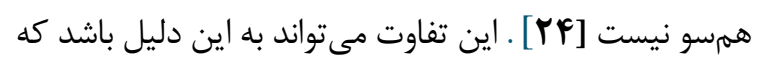

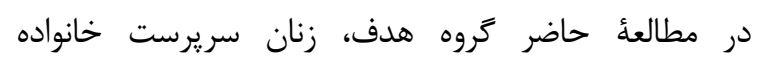

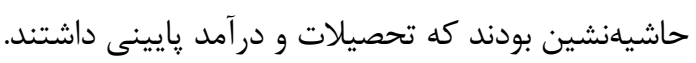

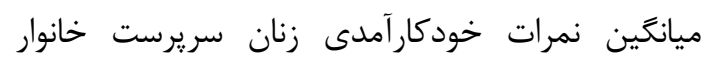

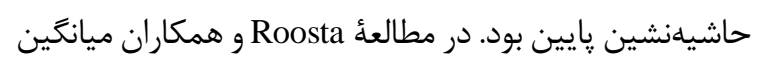

هدف از اين مطالعه بررسى ارتباط رفتارهاى ارتقادهنده

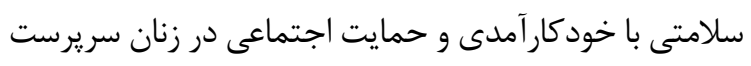

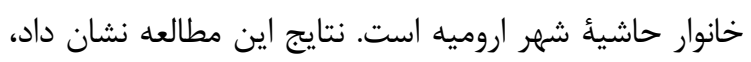

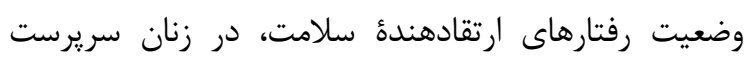
خانوار متوسط و يايين است و آنها بيشترين و كمترين نمره

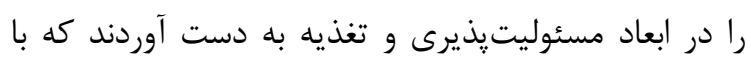

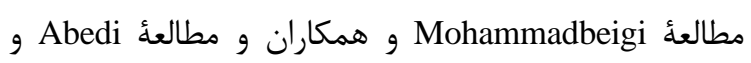

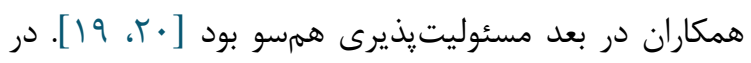
مطالعه Wei و همكاران و Raiyat و همكاران، كمترين نمره به بعد مسئوليتيذيرى سلامت مربوط بود كه با نتايج اين

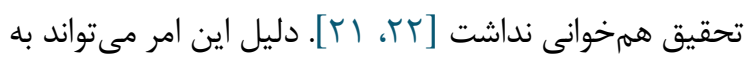


متغيرهاى خودكارآمدى، حمايت اجتماعى، متأهلبودن و

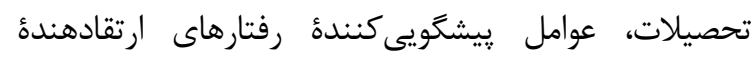
سلامت در زنان سريرست خانوار هستند.

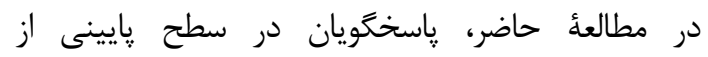

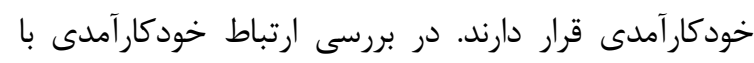

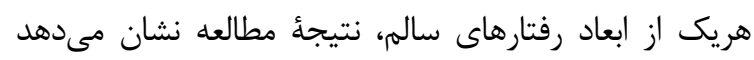

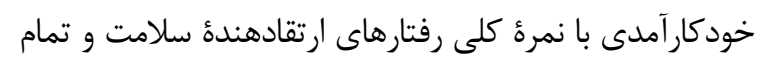

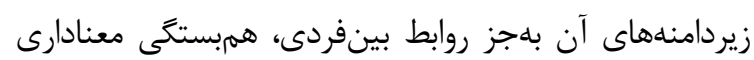

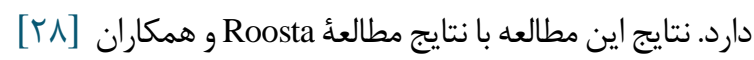

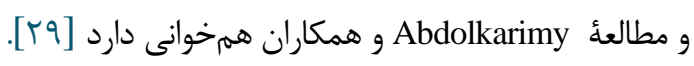

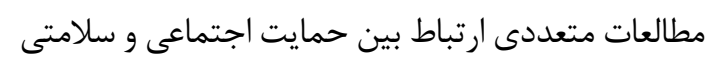

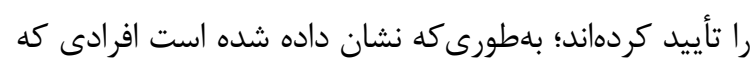

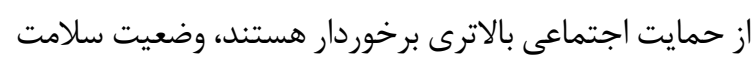

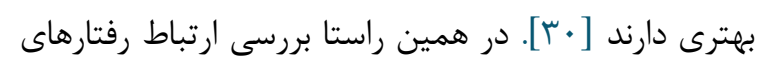

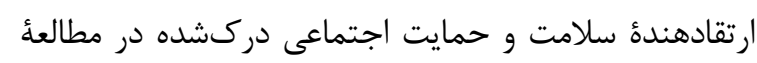

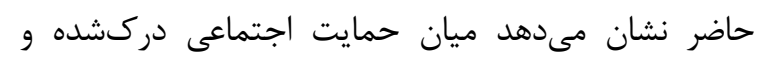

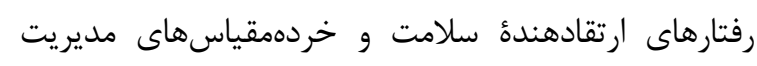

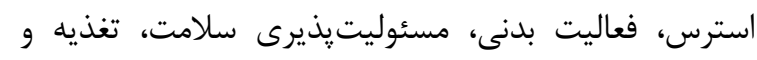

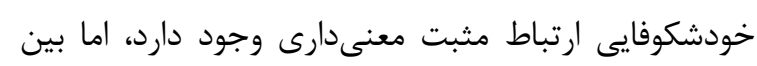

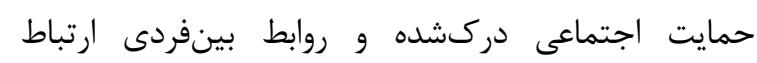

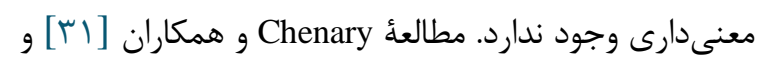

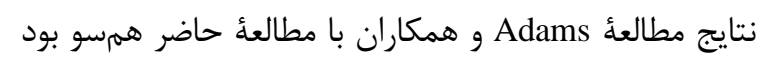

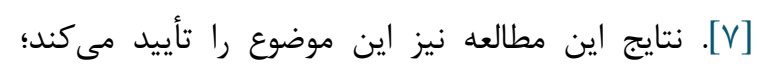

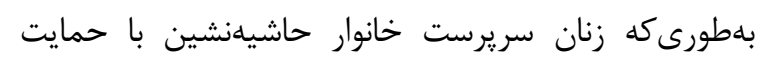
اجتماعى متوسط و پايين، وضعيت سلامت پاييينترى دارند.

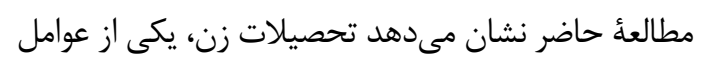

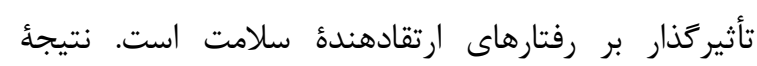

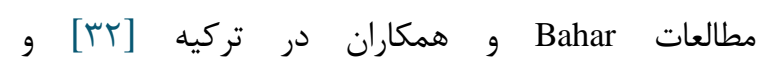
Mirghafourvand

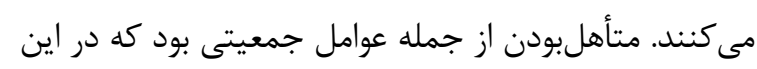
مطالعه بر رفتارهاى ارتقادهندهُ سلامت زنان أنان تأثيركذار بودئ

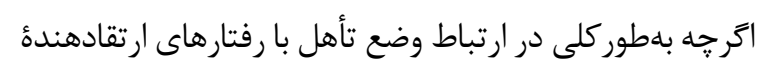
سلامت، تحقيقات مختلف نتيجأ يكسانى نداشتهاند، نتيجأ

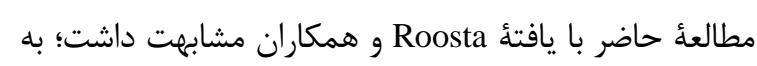

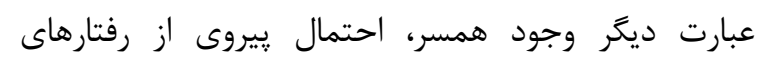

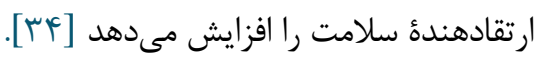

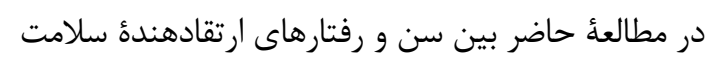
ارتباط معنىدارى وجود ندارد. دربارة اين موضوع يافتههاى
نمرات خودكارآمدى زنان سنين بارورى متوسط و بالاتر بود

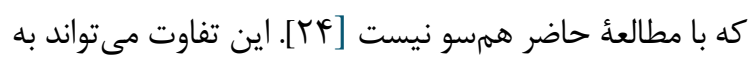

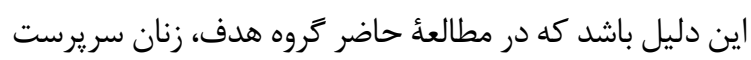

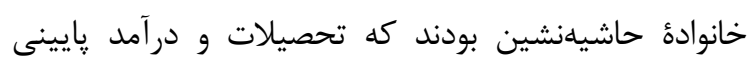

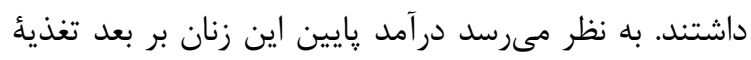
اين خانوارها تأثير منفى دارد.

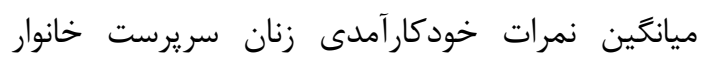

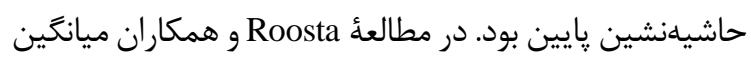

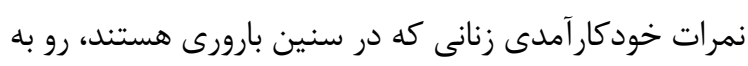

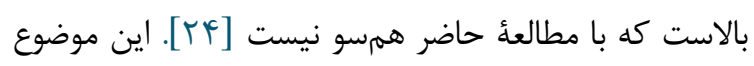

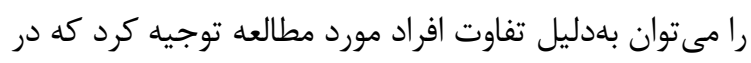

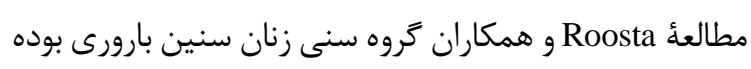

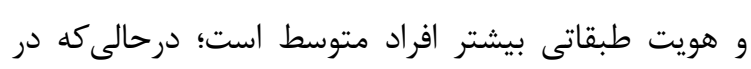

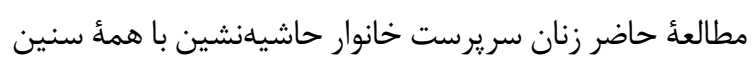
را شامل مىشد و بيشتر افراد وضعيت اقتصادى و تحصيلات

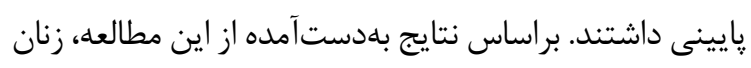

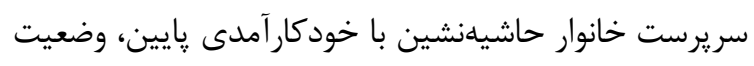
سلامت پايينترى دارند. در اين مطالعه ميانغين نمرات حمايت اجتماعى زناند

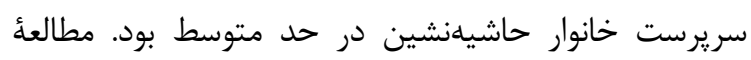
Khalili

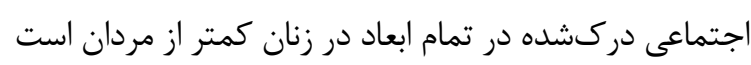

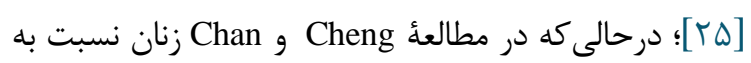

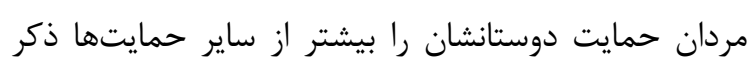
كردند [ع]ب. بيشتر زنان سريرست خانوار حاشيئ شهر، در اين مطالعه بيىسواد بودند يا تحصيلات آنها ابتدايى بود. سطح تحصيلات

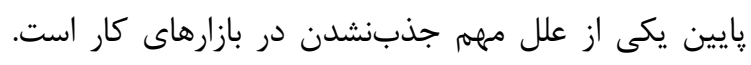

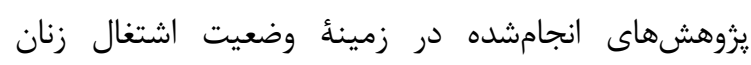

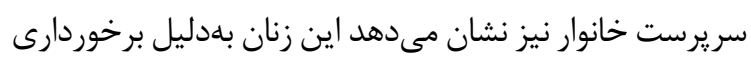

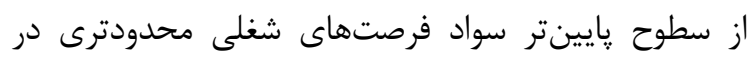

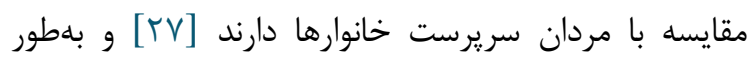

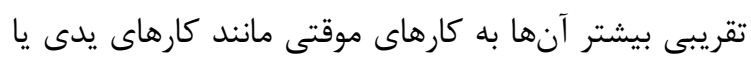

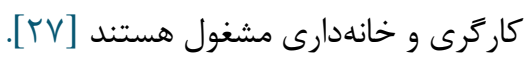

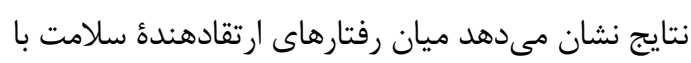

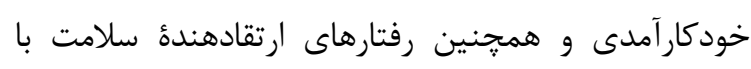
حمايت اجتماعى و مشخصات دموكر افيك (تحصيلات و تأهل) در زنان سريرست خانوار حاشيهنشين ارتباطى وجود دارد و 


$$
\text { نتيجه كَيرى }
$$

با توجه به يافتههاى يزوهش حاضر مىتوان نتيجه گرفت

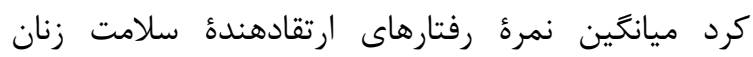

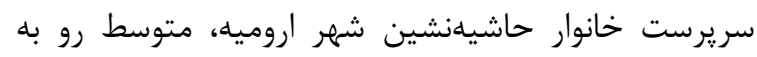
يايين است. با توجه به اين مطلب، اين گروه از زنان به توجه ويزه بهخصوص در بعد خودشكوفايى و تغذيه نياز دارند.

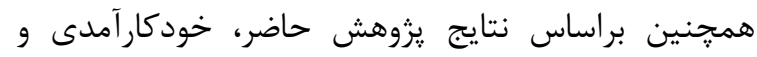

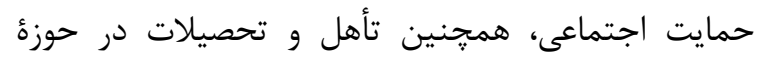
سلامت نيز بهعنوان عوامل مؤثر بر رفتارهاى ارتقادهندهُ هُهن سلامت در مطالعهُ حاضر تأييد شدند.

\section{سياسگَزارى}

نويسندگان از رياست محترم مركز بهداشت اروميه و

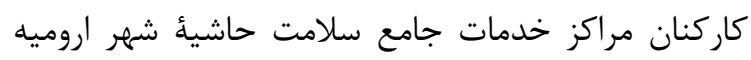
بابت مساعدت و همكارى در اين يزوهش كمال قدردانى را

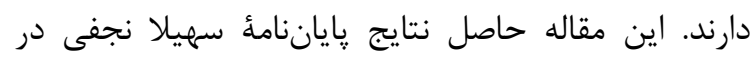

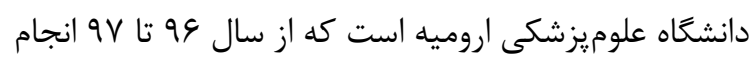

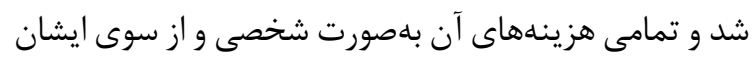
تقبل شده است.

$$
\text { تعارض در منافع }
$$

بين نويسندكان هيجَّونه تعارضى در منافع وجود ندارد

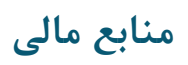

منابع مالى اين مطالعه توسط نويسندكان تامين شده است.
مطالعات مختلف نتايج ضد و نقيضى ارائه مى كند؛ جنانكه

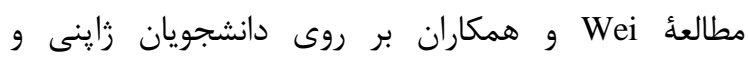
مطالعd Mahmoodi و همكاران همراستا با يافتههاى مطالعه حاضر سن را مرتبط با رفتارهاى ارتقادهنده سلامت نمى هماند

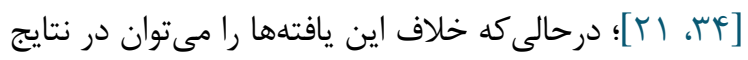

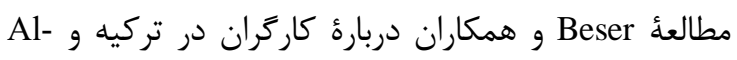
Kandari مشاهده كرد [צr، صَr]. در مطالعهُ حاضر بين وضعيت اشتغال و رفتارهاى

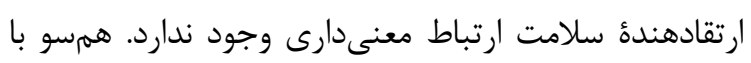

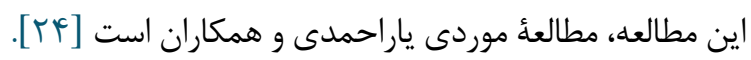

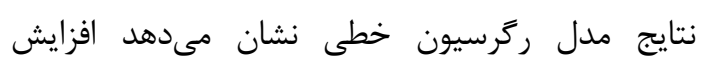

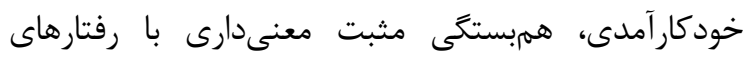

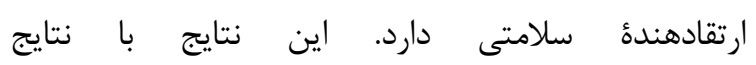

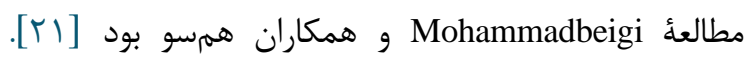
همجنين نتايج مدل ركرسيون خطى نشان مىدهد افزايش

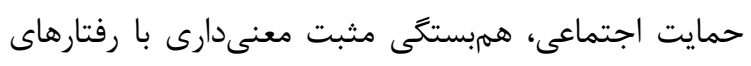

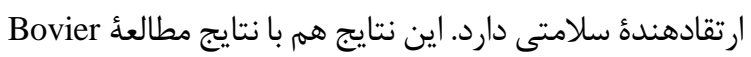

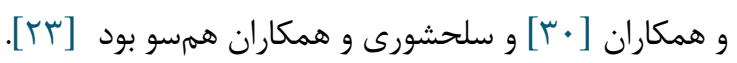
ييشنهاد براى يزوهش هاى بعدى

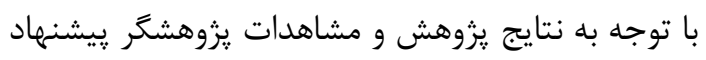

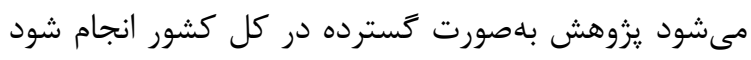

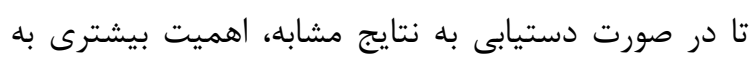

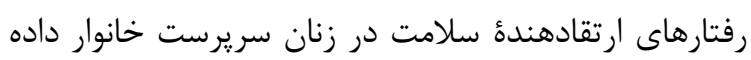

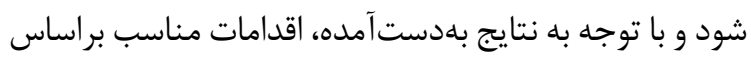

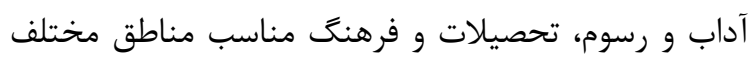
در نظر زرفته شود.

\section{References}

1. Parvizy S, Kiani K, Ivbijaro G. Women's health bridges and barriers: a qualitative study. Health care for women international. 2013;34(3-4):193-208. [DOI:10.1080/07399332.2012.740108] [PMID]

2. Van Leuven K, Prion S. Health promotion in care directed by nurse practitioners. The Journal for Nurse Practitioners. 2007;3(7):456-61. [DOI:10.1016/j.nurpra.2007.04.024]

3. Clark CC, Paraska KK. Health promotion for nurses: A practical guide. 1st ed. New York: Jones \& Bartlett Publishers; 2012.

4. Hong JF, Sermsri S, Keiwkarnka B. Health-promoting lifestyles of nursing students in Mahidol University. Journal of Public Health and Development. 2007;5(1):27-40.

5. Walker SN, Sechrist KR, Pender NJ. The health-promoting lifestyle profile: development and psychometric characteristics. Nursing research. 1987;36(2):76-81. [DOI:10.1097/00006199-198703000-00002] [PMID]

6. DiIorio C, Shafer PO, Letz R, Henry TR, Schomer DL, Yeager K, et al. Behavioral, social, and affective factors associated with self-efficacy for self-management among people with epilepsy. Epilepsy \& Behavior. 2006;9(1):158-63. [DOI:10.1016/j.yebeh.2006.05.001] [PMID] 
7. Adams MH, Bowden AG, Humphrey DS, McAdams LB. Social support and health promotion lifestyles of rural women. Online Journal of Rural Nursing and Health Care. 2000;1(1):28-40.

8. Taghavi M, Kalafi E, Talei A, Dehbozorgi G, Taghavi SMA. Investigating the Relation of Depression and Religious Coping and Social Support in Women with Breast Cancer. Journal of Isfahan Medical School. 2011;28(115).

9. Hamidi F. Relationship between Social support and mental health among Female-headed households employed a military university. JOURNAL OF MILITARY PSYCHOLOGY. 2010;1(2):51-60.

10. Gholipour A, Rahimian A. Economic, Cultural, and Educational Factors Related to Empowerment of Head-of-Household Women. Social welfare quarterly. 2011;11(40):29-62.

11. Kimiaee S. Methods Used for Empowering Head-of-Household Women. Social welfare quarterly. 2011;11(40):63-92.

12. Ozawa MN, Lee Y, Wang KY-T. Economic conditions of female-headed households in Taiwan in comparison with the United States and Sweden. Journal of Comparative Social Welfare. 2011;27(1):63-74. [DOI:10.1080/17486831.2011.532954]

13. Johansson H, Weinehall L, Emmelin M. " It depends on what you mean": a qualitative study of Swedish health professionals' views on health and health promotion. BMC health services research. 2009;9(1):191. [DOI:10.1186/14726963-9-191] [PMID] [PMCID]

14. Ghasemi R, Rjabi Gilan N, Reshadat S, Tavangar F, Saedi S, Soofi M. Quality of leisure time in women resident in marginal neighborhoods and its relation with health related quality of life. Journal of Mazandaran University of Medical Sciences. 2015;24(120):14-24.

15. Akinsola HA, Popovich JM. The quality of life of families of female-headed households in Botswana: A secondary analysis of case studies. Health care for women international. 2002;23(6-7):761-72. [DOI:10.1080/07399330290107502] [PMID]

16. Mohhamadi I, Pak A, Mohhamadi b. validity and reliabity of inarian version of health promoting behaviors. mazandaran medical journal. 2011;21:103-13.

17. Salimi A, Joukar B, Nikpour R. Internet and communication: Perceived social support and loneliness as antecedent variables. Psychological studies. 2009;5(3):81-102.

18. Zimet GD, Dahlem NW, Zimet SG, Farley GK. The multidimensional scale of perceived social support. Journal of personality assessment. 1988;52(1):30-41. [DOI:10.1207/s15327752jpa5201_2]

19. Abedi P, Jorfi M, Afshari P. Evaluation of the Health Promotion Lifestyle and its Related Factors in Reproductive Aged Women in Ahvaz, Iran. Community Health Journal. 2015;9(1):68-74.

20. Mohammadbeigi A, Anbari Z, Mohammadsalehi N, Mahdipour A, Ahmadli R, Ansari H. Study of the relationship between self-efficacy and health-promoting lifestyle and associated factors in nurses. Majallah-i Dānishgāh-i Ulūm-i Pizishkī-i Qum. 2016;10(7):49-57.

21. Wei C-N, Harada K, Ueda K, Fukumoto K, Minamoto K, Ueda A. Assessment of health-promoting lifestyle profile in Japanese university students. Environmental health and preventive medicine. 2012;17(3):222. [DOI:10.1007/s12199-0110244-8] [PMID] [PMCID]

22. Raiyat A, Nourani N, Samiei Siboni F, Sadeghi T, Alimoradi Z. Health Improving Behaviors in students of Qazvin Secondary schools in 2011. journal of health. 2012;3(3):46-53.

23. Salahshoori A, Harooni J, Salahshouri S, Hassanzadeh A, Mostafavi F, Molaei M. Investigation on association between self-efficacy, perceived barriers and social supports with health promoting behaviors in elderly in Dena city. Health system research. 2015;11(1):30-42.

24. Roosta F, Ahmadi A. Self-Efficacy and Health Promoting Behaviors among Women of Reproductive Ages in Shiraz During 2013. Journal of Ilam University. 2016;24(2):90-100. [DOI:10.18869/acadpub.sjimu.24.2.90]

25. Khalili F, Sam S, Sharifirad G, Hassanzadeh A, Kazemi M. The relationship between perceived social support and social health of elderly. Journal of Health System Research. 2012;7(6):1216-25.

26. Cheng S-T, Chan AC. The multidimensional scale of perceived social support: dimensionality and age and gender differences in adolescents. Personality and Individual Differences. 2004;37(7):1359-69. [DOI:10.1016/j.paid.2004.01.006]

27. Rimaz S, Dastoorpoor M, Vesali Azar Shorbeyani S, Saiepour N, Beigi Z, Nedjat S. The Survey of Quality of Life and its Related Factors in Female-headed Households Supported by Tehran Municipality, Ddistrict 9. Iranian Journal of Epidemiology. 2014;10(2):48-55.

28. Roosta F, Ahmadi A. Self-Efficacy and Health Promoting Behaviors among Women of Reproductive Ages in Shiraz During 2013. www sjimu medilam ac ir. 2016;24(2):90-100. [DOI:10.18869/acadpub.sjimu.24.2.90]

29. Abdolkarimy M, Zareipour M, Mahmoodi H, Dashti S, Faryabi R, Movahed E. Health Promoting Behaviors and their Relationship with Self-efficacy of Health Workers. Iran Journal of Nursing. 2017;30(105):68-79. [DOI:10.29252/ijn.30.105.68]

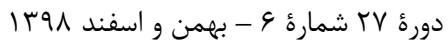

مجله مراقبت يرستارى و مامايى ابنسينا 
30. Bovier PA, Chamot E, Perneger TV. Perceived stress, internal resources, and social support as determinants of mental health among young adults. Quality of Life Research. 2004;13(1):161-70. [DOI:10.1023/B:QURE.0000015288.43768.e4] [PMID]

31. Chenary R, Noroozi A, Noroozi R. Relation between perceived social support and health promotion behaviors in chemical veterans in Ilam province on 2012-13. Iranian Journal of War and Public Health. 2013;6(1):1-10.

32. Bahar Z, Beşer A, Özbıçakçı Ş, Haney MÖ. Health promotion behaviors of Turkish women. Dokuz Eylül Üniversitesi Hemşirelik Fakültesi Elektronik Dergisi. 2014;6(1).

33. Mirghafourvand M, Baheiraei A, Nedjat S, Mohammadi E, Charandabi SM-A, Majdzadeh R. A population-based study of health-promoting behaviors and their predictors in Iranian women of reproductive age. Health promotion international. 2014;30(3):586-94. [DOI:10.1093/heapro/dat086] [PMID]

34. Mahmoodi H, Hasanpoor E, Zareipour M, Housaenpour H, Sharifi-Saqqezi P, Babazadeh T. Compare the health promoting behaviors among nurses, health and administrative staff. Iran Journal of Nursing. 2016;29(99):56-65. [DOI:10.29252/ijn.29.99.100.56]

35. Beser A, Bahar Z, BÜYÜKKAYA D. Health promoting behaviors and factors related to lifestyle among Turkish workers and occupational health nurses' responsibilities in their health promoting activities. Industrial health. 2007;45(1):151-9. [DOI:10.2486/indhealth.45.151] [PMID]

36. Al-Kandari F, Vidal VL. Correlation of the health-promoting lifestyle, enrollment level, and academic performance of College of Nursing students in Kuwait. Nursing \& health sciences. 2007;9(2):112-9. [DOI:10.1111/j.1442$\underline{2018.2007 .00311 . x]}$ [PMID] 


\section{بيوست}

جدول ضميمه شماره ا. واريانس ركرسيون خودكار آمدى و عوامل رفتارى

\begin{tabular}{|c|c|c|c|c|c|c|c|}
\hline \multirow{2}{*}{$\mathrm{R} 2$} & \multicolumn{3}{|c|}{ ضرايب رَّرسيون } & \multirow{2}{*}{ F آماره F } & \multirow{2}{*}{ دآزادى } & \multirow{2}{*}{ توان ديانكين } & \multirow{2}{*}{ منبع } \\
\hline & Pvalu & ضريب & متغير & & & & \\
\hline \multirow{3}{*}{ Trt } & $\cdot / \cdots$ & $9 / 90$ & ثابت (c) & \multirow{3}{*}{$\cdot 1 \cdots$} & \multirow{3}{*}{ r } & TFAT/K & رَرسيون \\
\hline & $\cdot 1 \cdots$ & $\cdot / F V$ & ورزش & & & $r V / \cdot \Lambda$ & ماندهها \\
\hline & $\cdot 1 \cdot \cdots$ & $\cdot / 49$ & مسئوليت & & & & مجموع \\
\hline
\end{tabular}

جدول ضميمه شماره r. واريانس رَّرسيون حمايت اجتماعى و عوامل رفتارى

\begin{tabular}{|c|c|c|c|c|c|c|c|}
\hline \multirow{2}{*}{$\mathrm{R} 2$} & \multicolumn{3}{|c|}{ ضرايب رَرسيون } & \multirow{2}{*}{ Fاره F F F } & \multirow{2}{*}{ درجه } & \multirow{2}{*}{ توان ديانگ } & \multirow{2}{*}{ منبع } \\
\hline & Pvalu & ضريب & متغير & & & & \\
\hline \multirow{3}{*}{$\cdot / 1 \Lambda$} & $\cdot 1 \cdots$ & $19 / 14$ & ثابت (c) & \multirow{3}{*}{$\cdot 1 \cdot$} & \multirow{3}{*}{$r$} & $r \mid \Lambda r / V$ & ركرسيون \\
\hline & $\cdot / \cdots$ & $\cdot 190$ & استرس & & & $V F / g T$ & ماندهها \\
\hline & $\cdot / \cdots$ & $\cdot|f|$ & تغذيه & & & & مجموع \\
\hline
\end{tabular}

